\title{
The Destombes-Rosai-Dorfman Disease or Sinus Histiocytosis with Massive Lymphadenopathy: A Rare Case Described in the Paediatrics Department of Yalgado Ouedraogo University Hospital
}

\author{
Chantal Zoungrana-Ouattara1,2*, Flore Ouédraogo1,2, Laure Toguyéni'2,3, Angèle Kalmogho1,2, \\ Caroline Yonaba1, ${ }^{1,}$, Chantal Gabrielle Bouda ${ }^{1}$, Rolande Kaboré ${ }^{1}$, Fla Kouéta ${ }^{1,2}$ \\ ${ }^{1}$ Département de pédiatrie du CHU Yalgado Ouédraogo de Ouagadougou, Ouagadougou, Burkina Faso \\ ${ }^{2}$ Unité de Formation et de Recherche en Sciences de la Santé (UFR/SDS), Université de Ouagadougou, Ouagadougou, Burkina Faso \\ ${ }^{3}$ Service de pédiatrie médicale du CHU Charles de Gaulle de Ouagadougou, Ouagadougou, Burkina Faso \\ Email: *chantalzoungrana@gmail.com
}

How to cite this paper: Zoungrana-Ouattara, C., Ouédraogo, F., Toguyéni, L., Kalmogho, A., Yonaba, C., Bouda, C.G., Kaboré, R. and Kouéta, F. (2017) The Destombes-RosaiDorfman Disease or Sinus Histiocytosis with Massive Lymphadenopathy: A Rare Case Described in the Paediatrics Department of Yalgado Ouedraogo University Hospital. Open Journal of Pediatrics, 7, 345-352. https://doi.org/10.4236/ojped.2017.74039

Received: November 24, 2017 Accepted: December 18, 2017 Published: December 21, 2017

Copyright (c) 2017 by authors and Scientific Research Publishing Inc. This work is licensed under the Creative Commons Attribution International License (CC BY 4.0).

http://creativecommons.org/licenses/by/4.0/ (c) (i) Open Access

\begin{abstract}
Destombes-Rosai-Dorfman' disease (DRD) is an inflammatory non-langerhansian histiocytosis with adenomegaly. It is a rare histiocytic disorder worldwide, less than 1000 reported cases. It is of unknown etiology and is characterized in its classical form by multiple adenomegalia, especially localized at cervical area, but also at mediastinal, axillary and inguinal areas. It is a benign condition, even if it is deforming, with spontaneously resolving evolution. We report a case of DRD disease in a 13-year-old girl, hospitalized in the Department of Pediatrics of the Yalgado Ouédraogo University Hospital Center in Ouagadougou, in March 2015. She was admitted for a voluminous bilateral painless cervical swelling, with no sign of local compression, having been operating for about a year. Biological tests showed signs of chronic inflammation; the imagery specified the benign character of these formations: adenomegalia. Confirmation of the diagnosis was made by pathological examination, describing the aspect of emperipolesis to histology and, immunohistochemistry, polytypic plasmacytosis and PS100 positive/CD1a histiocytosis negative. The treatment could not be properly carried out, in view of the early discharge, against medical advice from the patient. The evolution would have been marked, according to the parents, by a slight involution of swelling.
\end{abstract}

\section{Keywords}

Destombes-Rosai-Dorfman Disease, Emperipolesis, Immunohistochemistry, 
Yalgado Ouedraogo University Hospital

\section{Introduction}

Destombes-Rosai-Dorfman' s disease (DRD) is an inflammatory non-langerhansian histiocytosis with adenomegaly [1], described by Destombes in 1965 and later, better defined by Rosai and Dorfman in 1969 [2].

It is a clinicopathological entity rarely described, infant-juvenile (10 - 20 years), of chronic evolution; less than 1000 cases listed around the world according to the histiocyte society [3]. In Africa, a few cases have been described in North Africa (Morocco, Tunisia), but also in Black Africa (Gabon, Senegal). In Burkina Faso, two cases were reported by T. Konsem et al. in 2014, including a 9-year-old patient [4].

Its etiology remains poorly understood and unknown, as does its pathophysiology [2] [3]; It involves the production of non-langerhansian hystiocytes [3] [5]. The identification of familial cases of Destombes-Rosai-Dorfman disease (including identical twins) has suggested the possibility of genetic predisposition [6]. An association between DRD disease and autoimmunity has also been described in 15\% of cases [1] [2].

It is a pathology with a ubiquitous localization, whose classic form is ganglionic with cervical localization; generally, DRD disease is compatible with life [7]. Although lymphadenopathy can be bulky and disfiguring, it usually progresses to spontaneous remission. Rare and varied serious complications can be seen, related to the mode of revelation of the disease, with possibilities of death. The diagnosis of DRD disease is based on anatomopathological examination of a lymph node or affected organ [2] [8] [9]. The major histologic sign is the obstruction and distention of the histiocytic sinuses by a large histiocyte population; these histiocytes are clear cytoplasm, weakly eosinophilic, with one or more nucleolar vesicular chromatin nuclei [2] [10] [11]. Some contain in their cytoplasm, lymphocytes, more rarely plasma cells or intact polynuclear cells, surrounded by a clear border: images of emperipolesis sometimes also called lymphophagocytosis; it corresponds to the active penetration of the lymphocyte in the histiocytic or macrophagic cell without phagocytosis [11]. There is no mitosis or necrosis [2] [10]. The histological features of DRD disease are less specific in extra-ganglionic lesions: there are fewer dilated histiocytes and the presence of emperipolesis is rare [11].

Our goal was to report a case of DRD disease in a teenage girl, hospitalized in the paediatrics department of Yalgado Ouedraogo University Hospital.

Parents' free and informed consent was obtained before publish this case. The confidentiality of our patient's identity was guaranteed.

\section{Observation}

Our patient, 13 years old female, was admitted in March 2015, for a bilateral cer- 
vical swelling, evolving since one year on the date of admission. It was noted in history, the appearance of left supraclavicular and bilateral cervical swelling, becoming slightly sensitive, without signs of locoregional compression. They were associated with a vesperal intermittent fever, with a relatively well-preserved general condition

The evolution was towards a gradual increase in the volume of swelling, associated with a slight weight loss, despite the traditional treatments applied (decoctions for washing and drinking).

The anamnesis also found a second degree consanguinity in the parents, there was no notion of tuberculous contagion.

The physical examination found:

- A good general condition, with normal consciousness, and a moderate cutaneous paleness. Constants: $\mathrm{T}^{\circ}$ : $38.5^{\circ} \mathrm{C}$; FC: 95 bpm; FR: 18 c/min; TA: 110/80 mmHg; BMI: $16.45 \mathrm{~kg} / \mathrm{m}^{2}$

- Multiple cervical and supraclavicular polyadenopathy, of variable size: from 6 to $12 \mathrm{~cm}$ of large diameter, firm, mobile in relation to the superficial plane and fixed in the deep plane; slightly sensitive. They gave our patient the appearance of a proconsular neck (Figure 1 and Figure 2).

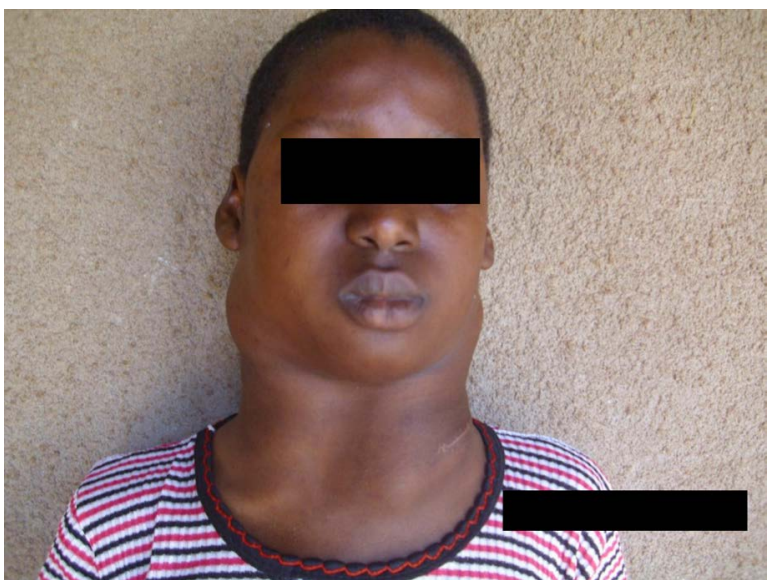

Figure 1. Front view: bilateral cervical lymphadenopathy giving proconsular neck.

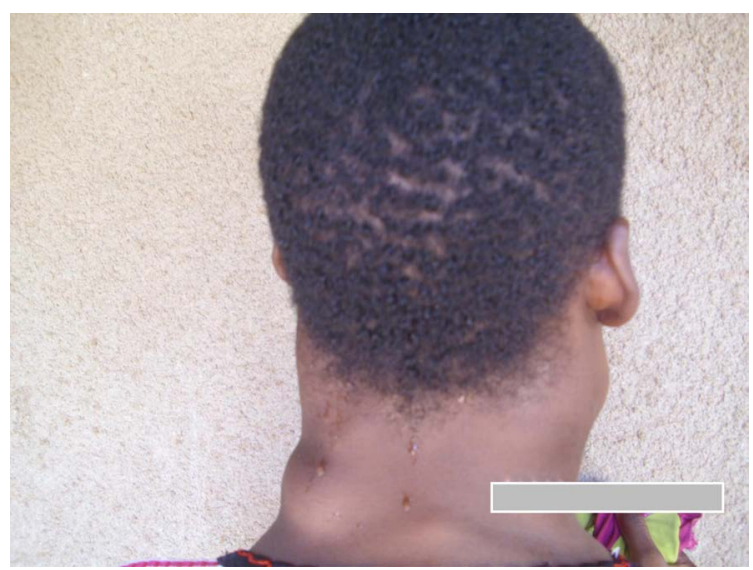

Figure 2. Back view. 
- Elsewhere, the physical examination did not note hepatomegaly, splenomegaly, or any sign of life-threatening distress.

Radiology confirms the presence of lymphadenopathy by:

- Cervical ultrasonography: Bilateral and comparative exploration showed almost identical anomalies on both sides of the neck, like innumerable tissue formations, well-defined, inhomogeneous, without necrosis signs, and suggestive of lymphadenopathy, measuring up to $60 \mathrm{~mm}$ in their major axis.

- The frontal chest $\mathrm{x}$-ray showed mediastinal lymphadenopathy enlarging the mediastinum without other lesions associated (pulmonary parenchyma, pleura, or bones).

- The cervicothoracic scan located the lymphadenopathy, specifying the invasion of the latero cervical ganglionic areas bilaterally, jugular, carotid, submandibular, supraclavicular and mediastinal, associated with polypoid thickening of the maxillary, ethmoidal, sphenoidal and front sinuses (Figure 3 and Figure 4).

In the context of etiological research:

- The tuberculin IDR was negative.

- The myelogram was normal.

- Biological examinations noted signs of chronic inflammation.

- Histopathological examination of cervical adenomegaly noted:

o In histology: lymphoid hyperplasia with sinus histiocytosis (the architecture of the ganglia is preserved, histiocytic sinuses are enlarged containing hyperplastic

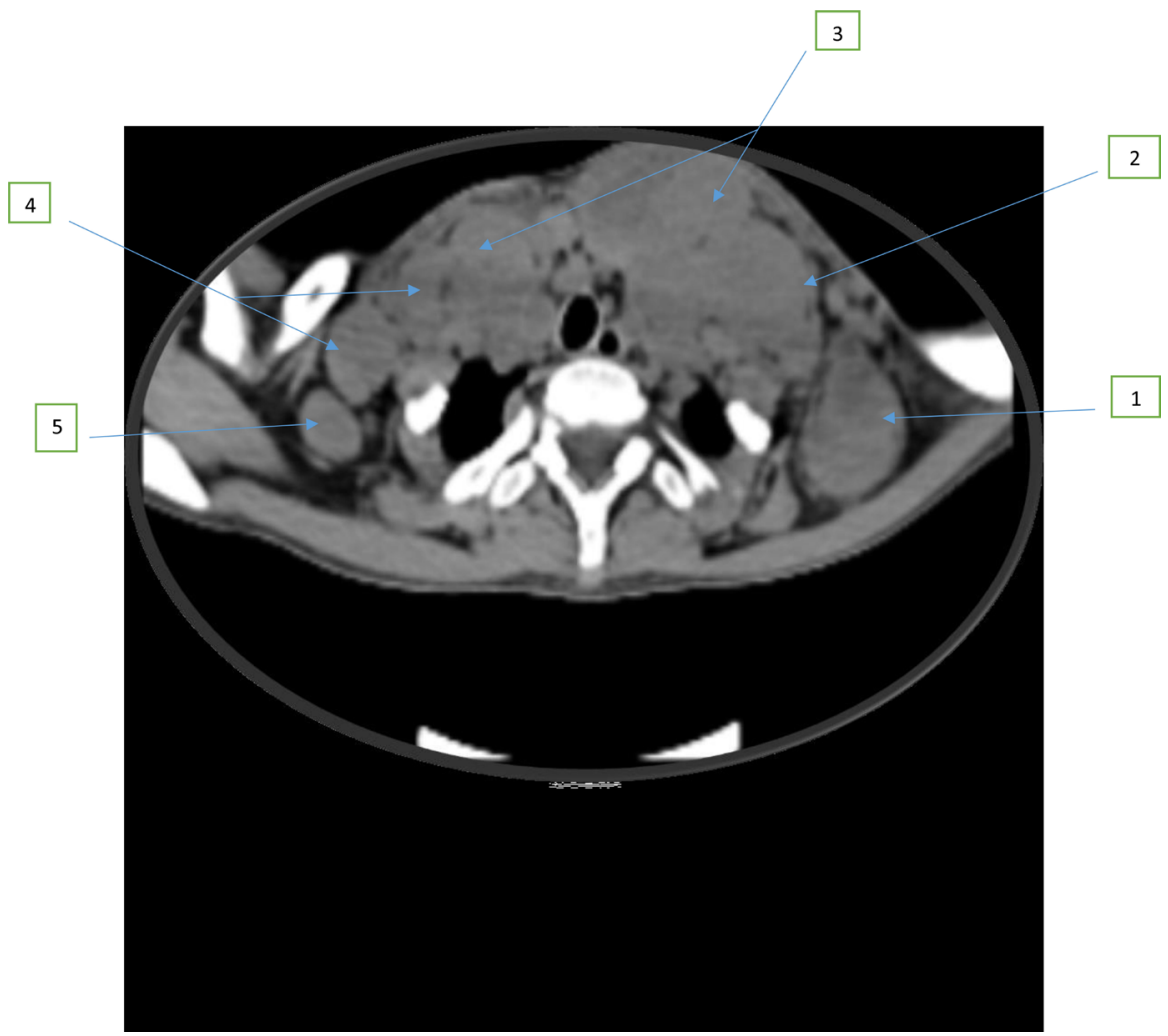

Figure 3. CT scan cervical cut showing multiple adenomegalies $(1 \ldots, 5)$. 


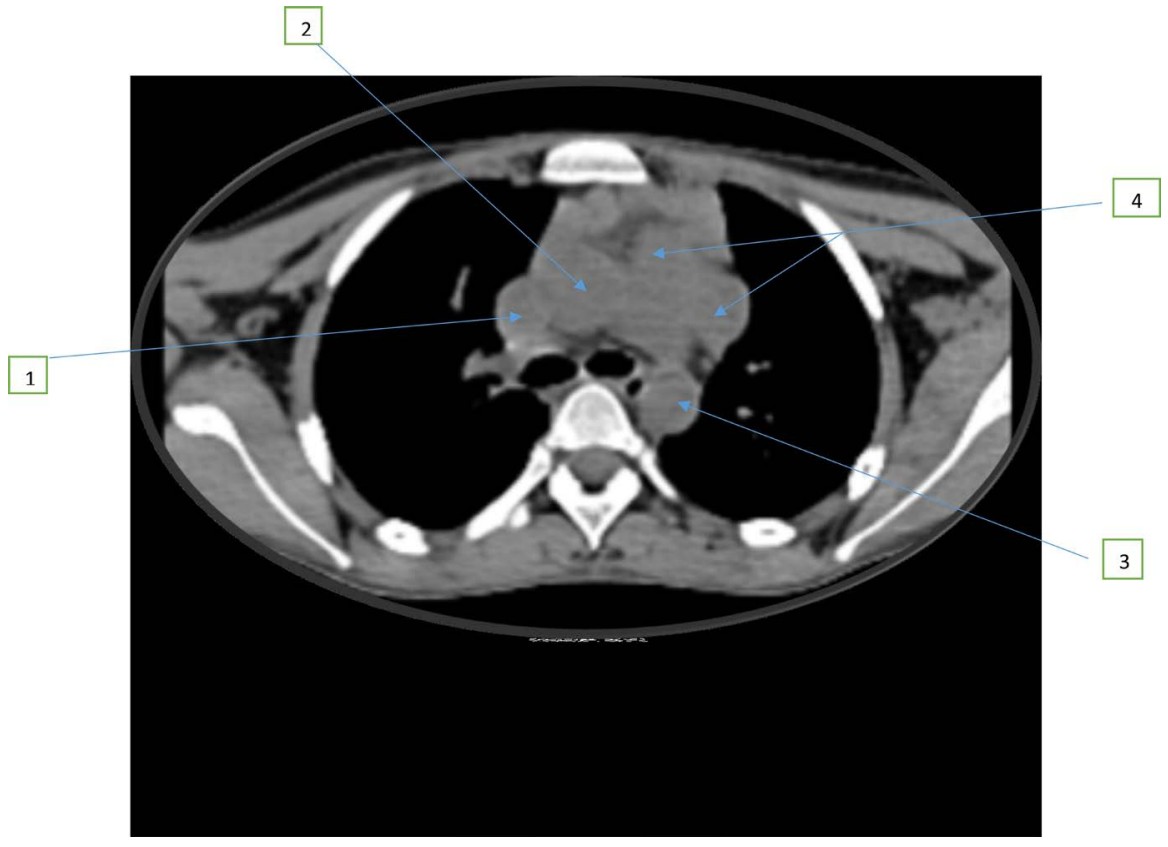

Figure 4. CT chest section: $(1-4)$ adenomegalies.

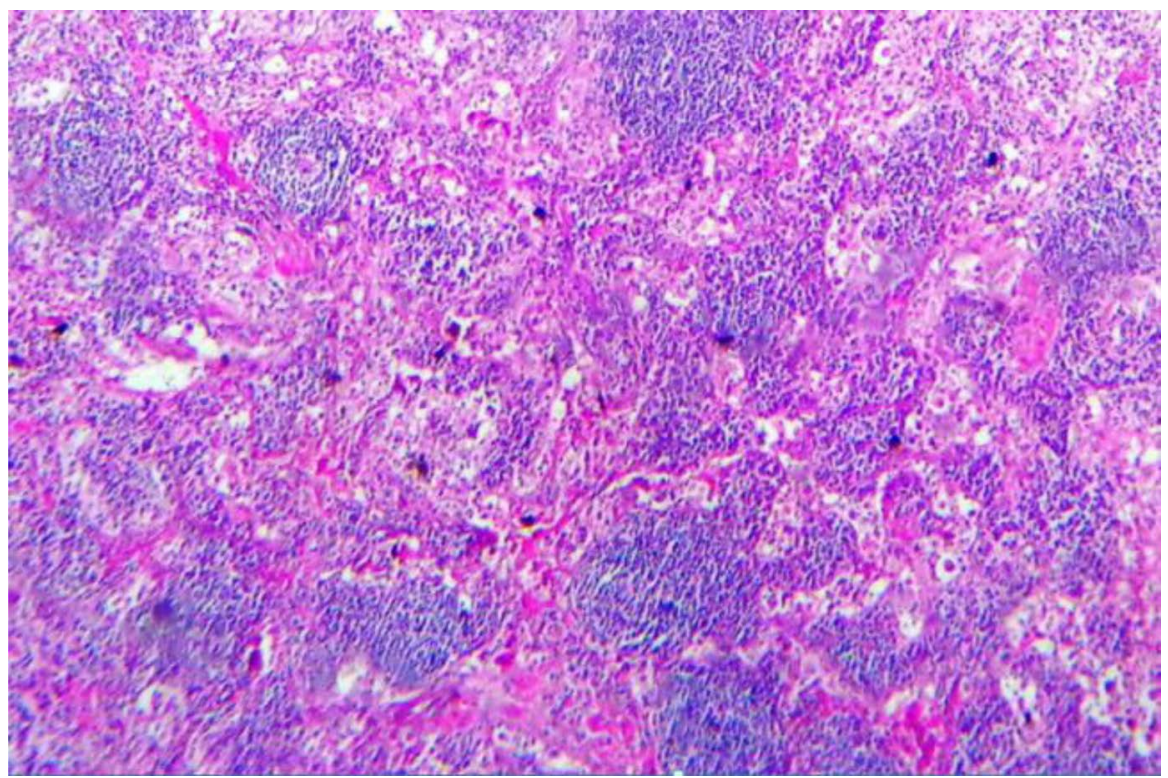

Figure 5. Histological examination images of the cervical adenectomy piece $(\mathrm{MO} \times 5)$.

lymphoid follicles importantly (Figure 5 and Figure 6).

o In immunohistochemistry: an old and remodeled chronic lymphadenitis lesion, characterized by sinus tract filling by both polytypic plasmacytosis and PS100+/CD1a-histiocytosis.

Our patient received oral corticosteroid therapy with prednisone for 10 days.

The patient came out against the opinion of the medical staff; she has never been reviewed. However the evolution would have been marked, (according to the parents (joined by telephone), by a slight involution of the swelling. Our patient continues her daily activities without hindrance. 


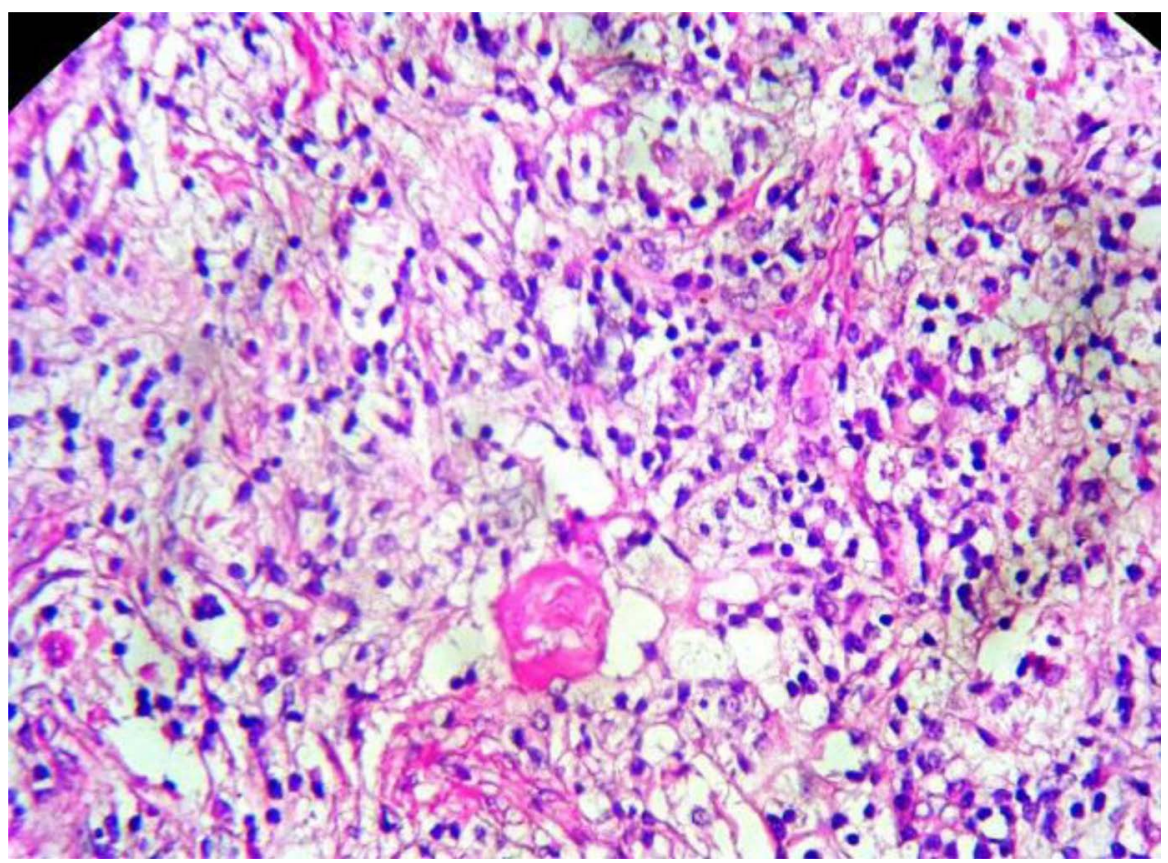

Figure 6. Histological examination images of the cervical adenectomy piece $(\mathrm{MO} \times 40)$.

\section{Discussion}

DRD disease is a rare histiocytic pathology (less than 1000 cases reported) and little known [3]. In Burkina Faso, our patient seems to be the third case reported. The previous ones were described in 2014 by Konsem et al. [4]. A discreet masculine predominance ( 4 men for 3 women) is found, as well as in black people or African descent [3]. The patient was 13 years old, E. Foucar reported that Destombes-Rosai-Dorfman's disease mainly affected the child and the young adult: $80 \%$ of the patients registered in the international register that year, were aged under 20 years old and $2 / 3$ younger than 10 years old [11] [12]. The diagnosis should be evoked in the presence of massive atypical lymphadenopathy, essentially characterized by bilateral large painless cervical ganglia,, of chronic evolution occurring in the child or adolescent with the general condition preserved; although isolated or associated extra ganglionic sites may exist [8] [12] [13].

Imagery informing about the extent of the lesions and their benign nature [14].

However, in our context, the differential diagnosis should be made with much more serious diseases such as ganglionic tuberculosis, Hodgkin lymphoma or non-Hodgkin's lymphoma, and leukemia, these diagnoses were mentioned in our patient.

Histopathological examination of adenomegaly confirms the diagnosis by showing images of empiripolesis on histology and immunhistochemistry, a positive response to PS100, CD68 and CD1a negative [12] [14]. This type of exam is not available in our working context, explaining an atypical diagnostic route [4]. Indeed, two histological examinations were required for the diagnosis; the first histological examination concluded to chronic hyperplastic lymphadenitis, without cha- 
racters of malignancy. This analysis requires the expertise of an experienced pathologist, at the risk of misinterpretation. This error was also reported by Konsem et al. [4]. The anatomopathological diagnostic difficulty was found in all cases reported by teams in Burkina Faso, including ours. It is a priority to surround yourself with all the necessary skills to obtain the best diagnoses.

Pathological examination was also useful to eliminate the other hypotheses of the differential diagnosis: no tuberculoid granuloma, no foci of necrosis, and no sign of malignancy.

The patient had short oral corticosteroid treatment for 10 days. The DRD disease treatment is poorly codified; ranging from prolonged corticosteroid therapy to radiotherapy, surgery and chemotherapy [4] [8] [13]. However, 50\% of patients do not use any treatment [7] and authors like Gallicier argue that swelling is spontaneously resolving in a significant proportion of patients, within 5 years [12].

DRD disease is chronic and can last for several years with periods of spontaneous remission and exacerbations [4] [7] [8] [13]. According to Foucar, healing would be complete in $23 \%$ of cases [11].

\section{Conclusion}

The DRD disease raises diagnostic and therapeutic challenges, requiring a strong multidisciplinary collaboration for its management.

\section{References}

[1] Cohen Aubart, F., Haroche, J., De Risi, T., Barkaoui, M., Charlotte, F., Sene, T., Bernard, C., Galicier, L., Chaminade, A., Hervier, B., Kahn, J.E., Tazi, A., Donadieu, J. and Amoura, Z. (2015) La maladie de Rosai Dorfman Destombes est une histiocytose inflammatoire polymorphe: étude phénotypique multicentrique de 47 patients. La revue de médecine interne, 36, A40-A41. https://doi.org/10.1016/j.revmed.2015.03.267

[2] Miranda Roberto, N., Khoury, J.D. and Medeiros, L.J. (2013) Atlas of Lymph Node Pathology, Chapter 24. Springer, Berlin, 97-100.

https://doi.org/10.1007/978-1-4614-7959-8_24

[3] Abstracts of the Histiocyte Society 26th Annual Meeting. Boston, Massachusetts. https://doi.org/10.1002/pbc.23084

[4] Konsem, T., Wend-Lasida Ouedraogo, R., Millogo, M., Gyebre, Y.M.C., Bouaichi, A. and Zwetyenga, N. (2014) Two Cases of Sinus Histiocytosis with Massive Cervical Lymphadenopathy (Destombes-Rosai-Dorfman Disease). Revue de stomatologie, de chirurgie maxillo-faciale et de chirurgie orale, 115, 313-317. https://doi.org/10.1016/j.revsto.2014.04.003

[5] Talaoui, M., Skalli, A., Elouardi, E.Z., Elamraoui, F. and Chikhaoui, N. (2006) Maladie de Rosai-Dorfman: à propos d'une localisation musculaire. Journal de Radiologie, 87, 1478-1478. https://doi.org/10.1016/S0221-0363(06)87664-X

[6] Rossbach, H.C., Dalence, C., Wynn, T. and Tebbi, C. (2006) Faisalabad Histiocytosis Mimics Rosai Dorfman Disease: Brothers with Lymphadenopathy, Intrautérine Fractures, Short Stature, and Sensorineural Deafness. Pediatric Blood \& Cancer, 47, 629-632. https://doi.org/10.1002/pbc.20605

[7] Pulsoni, A., Anghel, G., Falcucci, P., Matera, R., Pescarmona, E., Ribersani, M., Vil- 
livà, N. and Mandelli, F. (2002) Treatment of Sinus Histiocytosis with Massive Lymphadenopathy (Rosai-Dorfman Disease): Report of a Case and Literature Review. American Journal of Hematology, 69, 67-71. https://doi.org/10.1002/ajh.10008

[8] Ben Turkia, H., Ben Rodhane, M., Azzouz, H., Ben Chehida, A., Abdemoula, M.S., Benabdelaziz, R., et al. (2011) La maladie de Rosai-Dorfman: A propos de deux observations. La Tunisie médicale, 89, 497-501.

[9] Joubert, C., Degain, A., Faivre, A., Nguyen, A.-T., Fesselet, J. and Figarella-Branger, D. (2013) Une maladie de Rosai-Dorfman intracrânienne mimant des méningiomes multiples. Revue Médicale de Bruxelles, 34, 112-114.

[10] Chetaille B. (2007) Pièges morphologiques et immunohistochimiques en pathologie ganglionnaire Histoséminaire carrefour pathologie. SFP, 19-23.

[11] Foucar, E., Rosai, J. and Dorfman, R. (1990) Sinus Histiocytosis with Massive Lymphadenopathy (Rosai-Dorfman Disease): Review of the Entity. Seminars in Diagnostic Pathology, 7, 19-73.

[12] Galicier, L., Fieschi, C., Meignin, V., Clauvel, J.P. and Oksenhendler, E. (2007) Histiocytose sinusale de Rosai-Dorfman. La Presse médicale, 36, 1669-1675. https://doi.org/10.1016/j.lpm.2007.06.008

[13] Belembaogo, E., Sanou, S., Nzenze, J.R., Girinski, T. and Nguemby Mbina, C. (1999) Rosai-Dorfman Disease. Médecine d'Afrique Noire, 46, 123-124.

[14] Jemni, H., Chekir, N., Oueslati, S., Bakir, D., Hammami, N., Tlili, K., et al. (1997) Histiocytose sinusale ou maladie de Rosai-Dorfman. A propos d'une localisation orbitaire. Journal d'Echographie et de Médecine par Ultrasons, 18, 260-264. 